\title{
Assay of Clopidogrel by Using HPLTC Method
}

\author{
Dr. D. S. Ghotekar ${ }^{1}$, Vishal N. Kushare ${ }^{2}$
}

${ }^{1}$ Department of Chemistry, N.V.P.Mandal's, Arts, Commerce and Science College Lasalgaon

Tal-Niphad, Dist-Nashik, Maharastra, India

2Department of Pharmaceutics, Maratha Vidya Prasarak Samaja's Institute of Pharmaceutical

Sciences, Adgaon, Nashik, Maharastra, India

\begin{abstract}
The present paper describes stability indicating high-performance thin-layer chromatography (HPTLC) assay method for clopidogrel in bulk drugs. The method employed TLC aluminium plates precoated with silica gel 60F-254 as the stationary phase. The solvent system consisted of toluene: methanol: triethylamine (6.5: 4.0: 0.1 $\mathrm{v} / \mathrm{v} / \mathrm{v})$. The system was found to give compact spot for clopidogrel $\left(\mathrm{R}_{\mathrm{f}} \mathrm{value}\right.$ of $\left.0.40 \pm 0.010\right)$. Densitometric analysis of Clopidogrel was carried out in the absorbance mode at $254 \mathrm{~nm}$. The linear regression analysis data for the calibration plots showed good linear relationship with $\mathrm{r} 2=0.888$ with respect to peak area in the concentration range 30 - $120 \mathrm{ng} / \mathrm{spot}$.
\end{abstract}

Keywords : Clopidogrel, Validation, HPTLC

\section{INTRODUCTION}

High Performance Thin Layer Chromatography (HPTLC) is the most powerful advanced form of Thin Layer Chromatography (TLC) and consists of chromatographic layers of utmost separation efficiency and the application of sophisticated instrumentation for all steps in the procedure include accurate sample application, standardized reproducible chromatogram development and software controlled evaluation. HPTLC is a concept that includes a widely standardized methodology based on scientific facts as well as the use of validated methods for qualitative and quantitative analysis. HPTLC meets all quality requirements for today's analytical labs, to increase the resolution and to allow more accurate quantitative measurements.
HPTLC is the most advanced form of modern TLC. It uses HPTLC plates featuring small particles with a narrow size distribution which results in homogenous layers with a smooth surface to be obtained. HPTLC uses smaller plates $(10 \times 10$ or $10 \times$ $20 \mathrm{~cm}$ ). HPTLC plates provide improved resolution, higher detection sensitivity, and improved in situ quantification and are used for industrial pharmaceutical densitometric quantitative analysis. Normal phase adsorption TLC on silica gel with a less polar mobile phase, such as chloroform- methanol, has been used for more than $90 \%$ of reported analysis of pharmaceuticals and drugs.

The selection of mobile phase is based on adsorbent material used as stationary phase and physical and chemical properties of analyte. The mobile-phase systems are used based on their diverse selectivity 
properties are diethyl ether, methylene chloride, and chloroform combined individually or together with hexane as the strength adjusting solvent for normalphase TLC and methanol, acetonitrile, and tetrahydrofuran mixed with water for strength adjustment in reversed-phase TLC. Separations by ion pairing on $\mathrm{C}-18$ layers are done with a mobile phase such as methanol-0.1 M acetate buffer ( $\mathrm{pH}$ 3.5) containing $25 \mathrm{~mm}$ sodium pentanesulfonate (15.5:4.5).

\section{EXPERIMENTAL WORK}

\section{Standard Solutions}

- Solution A (Stock Standard Solution)

Accurately weighed quantity of Clopidogrel (10.0 $\mathrm{mg}$ ) was dissolved in methanol to make $10.0 \mathrm{ml}$ solution. (conc.: $1.0 \mathrm{mg} / \mathrm{ml}$ ).

- Solution B (Working Standard Solution)

Accurately measured $1.0 \mathrm{ml}$ of solution A was diluted to $100.0 \mathrm{ml}$ with methanol (conc.: 10.0 $\mu \mathrm{g} / \mathrm{ml})$.

\section{* Optimization of chromatographic conditions}

\section{- Optimization of mobile phase}

Aliquot portions of working standard solution (5 $\mu \mathrm{l}$ ) were applied on TLC plates. Various pure solvents with varying polarity and their mixtures were tried for optimum movement of drug with sharp symmetrical peak. After trying several permutations and combinations, the mobile phase containingtoluene: methanol: triethylamine (6.5: 4.0: $0.1 \mathrm{v} / \mathrm{v} / \mathrm{v}$ ) was found to be most satisfactory as it gave sharp symmetrical peaks for the drug with $R_{F}$ values $0.40 \pm 0.010$.

- Optimization of wavelength for densitometric evaluation

Aliquot portion of working standard solution B $(5 \mu \mathrm{l})$ was applied on TLC plate. The plate was developed using optimized mobile phase. After development, the plate was removed and dried with the help of hair dryer. The migrated band was scanned over the wavelength range 200- 400 $\mathrm{nm}$ in an absorbance/reflectance mode and an in situ UV-absorption spectrum of drug was obtained.

A $254.0 \mathrm{~nm}$ was selected as scanning wavelength as it gave maximum absorption for the drug.

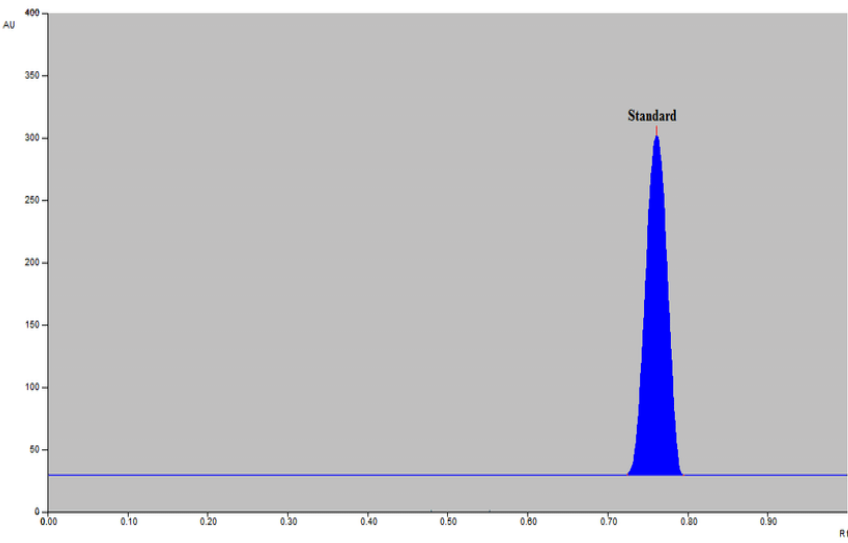

(a)

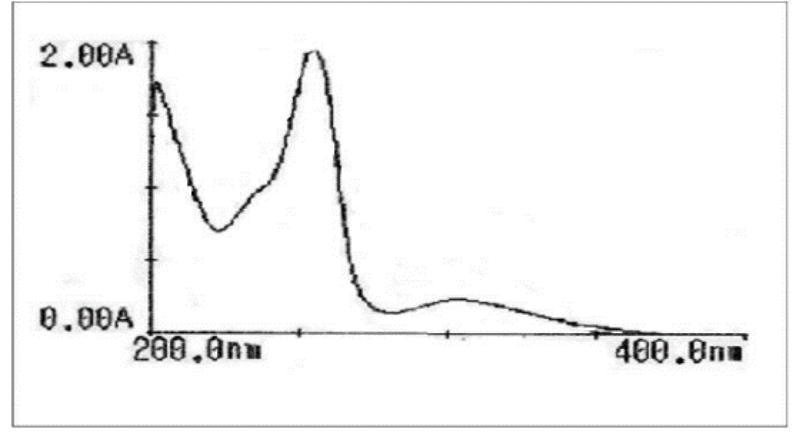

(b)

Figure 1 : (a) HPTLC chromatogram and (b) In situ UV Spectrum of clopidogrel

\section{- Chamber saturation time}

The chamber saturation time was optimized by allowing the spotted plates to equilibrate for varying time with vapours of mobile phase in twin trough chamber and then developing them using optimized mobile phase. The optimum saturation time was found to be $15 \mathrm{~min}$, which resulted in to dense and compact spot. 
On the basis of exhaustive experimentation the chromatographic conditions optimised are as follows:

\begin{tabular}{|l|l|}
\hline Stationary Phase & $\begin{array}{l}\text { Pre-coated Silica Gel 60 } \\
\text { F254 TLC Plate }(10 \times 10 \\
\mathrm{cm})\end{array}$ \\
\hline Thickness & $200 \mathrm{~mm}$ \\
\hline Mobile Phase & Toluene Methanol \\
\hline Mode of Application & Band \\
\hline Band Width & $5 \mathrm{~mm}$ \\
\hline Sample Volume & $5 \mathrm{ml}$ \\
\hline Separation Technique & Ascending \\
\hline & $\begin{array}{l}\text { Twin trough glass } \\
\text { chamber }, 10 \times 10 \mathrm{~cm}\end{array}$ \\
\hline Development Chamber & $15 \mathrm{~min}$ \\
\hline Chamber Saturation Time & $90 \mathrm{~mm}$ \\
\hline Migration Distance & UV Densitometric \\
\hline & Scanning \\
\hline Detection & Absorbance/ \\
\hline & Reflectance \\
\hline Scanning Mode & $254.0 \mathrm{~nm}$ \\
\hline Scanning Wavelength & $20 \mathrm{~mm} / \mathrm{s}$ \\
\hline Scanning Speed & $4.0 \times 0.45 \mathrm{~mm}$ \\
\hline Slit Dimension & $25 \pm 3{ }^{\circ} \mathrm{C}$ \\
\hline Temperature & \\
\hline
\end{tabular}

The samples of stress studies were spotted ( $5 \mu \mathrm{l}$ bands) on TLC plates and developed and scanned under optimized conditions. The study has shown adequate resolution of parent drug and its degradation products from one another under optimized chromatographic conditions by normal phase mode. Hence these chromatographic conditions were finalized for further experimentation.
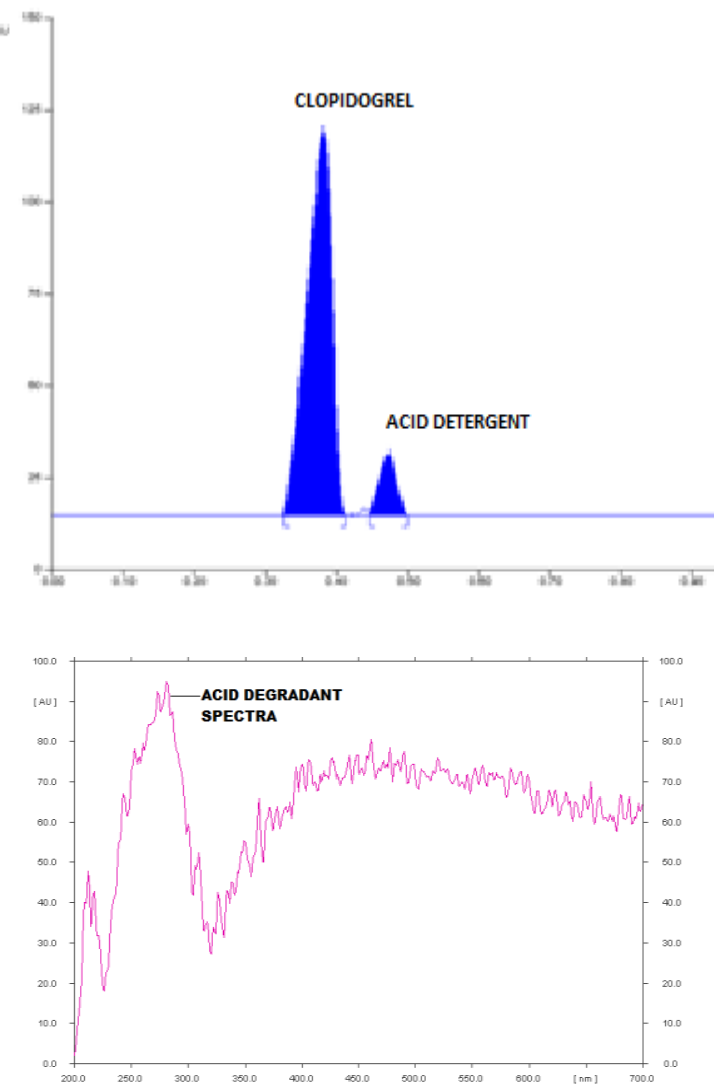
A) Acid (1M HCL, $24 \mathrm{~h}$ reflux) and Spectra of degradant
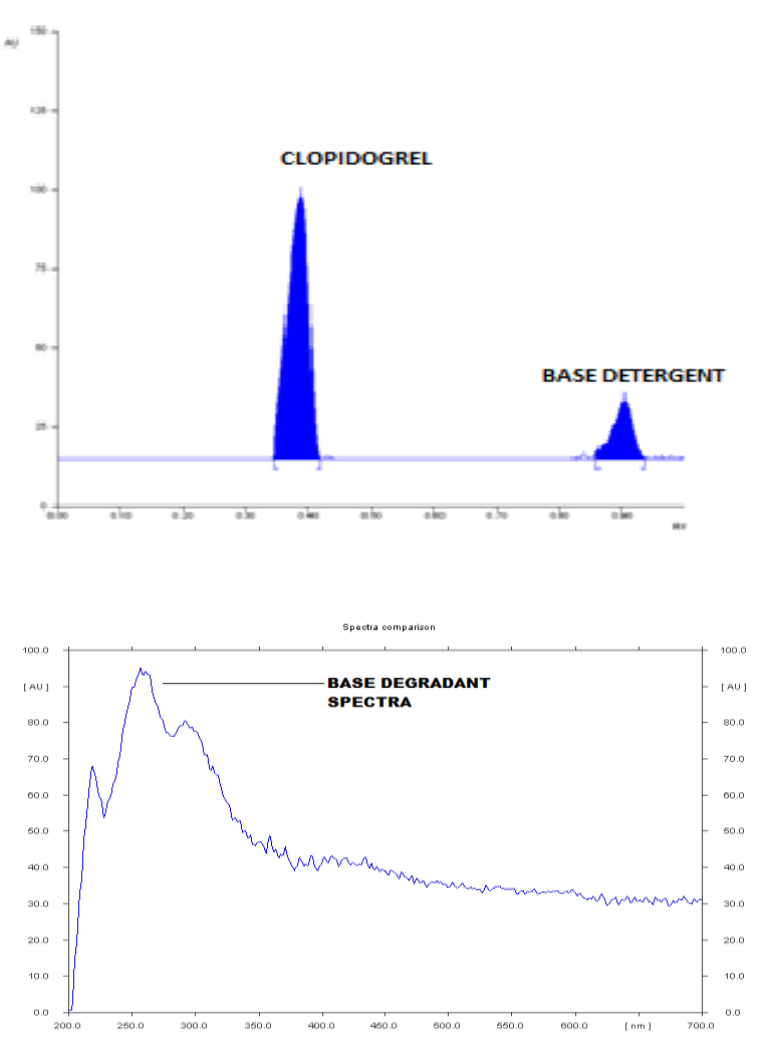

B) Base (1M NaOH, $24 \mathrm{~h}$ reflux $)$ and Spectra of degradant 


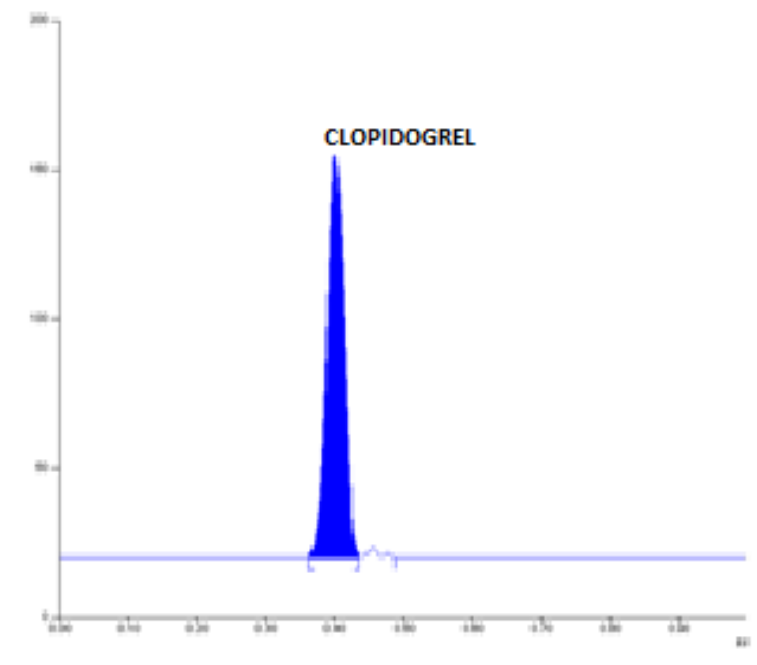

C) Neutral stress, $24 \mathrm{~h}$ reflux

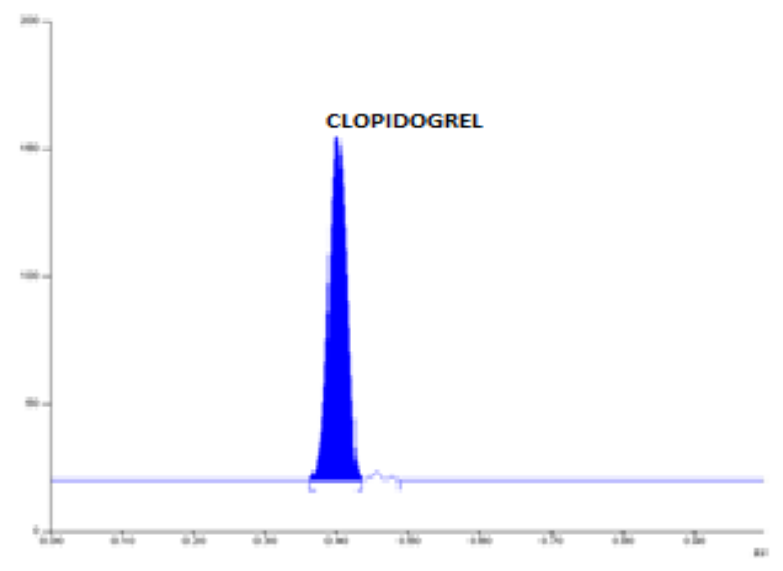

D) Oxidative stress $\left(3 \% \mathrm{H}_{2} \mathrm{O}_{2}, 48 \mathrm{~h}\right.$ at R.T.

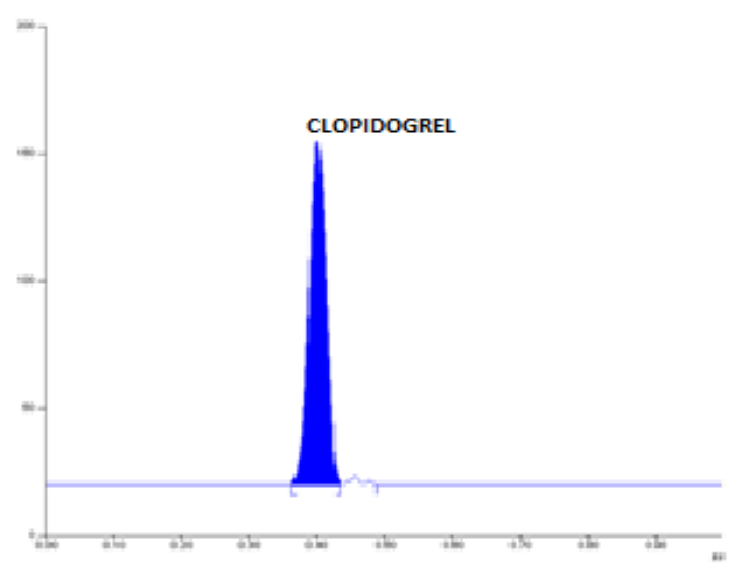

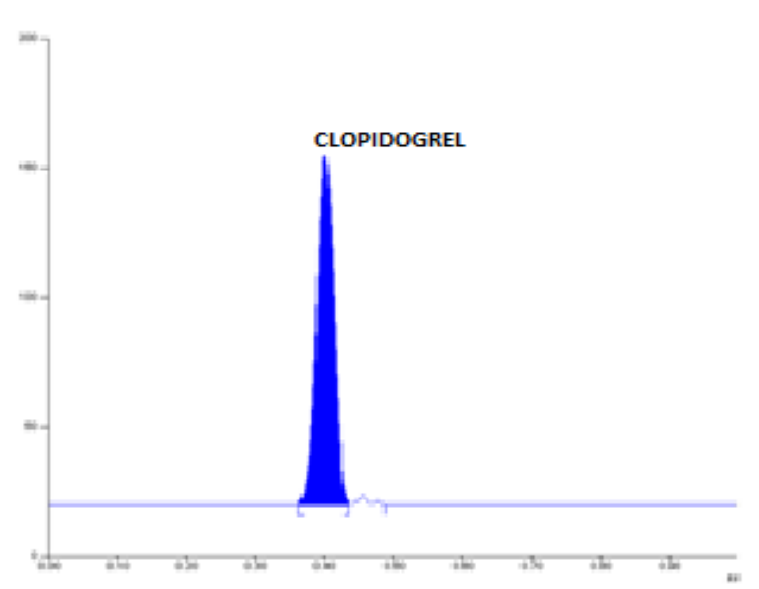

E) Photolytic Stress, (15 days, 4 lac lux h) F) Thermal Stress (dry heat, 15 days at $700 \mathrm{c}$

Figure 2 : HPTLC chromatograms of forced degraded samples (A-F).

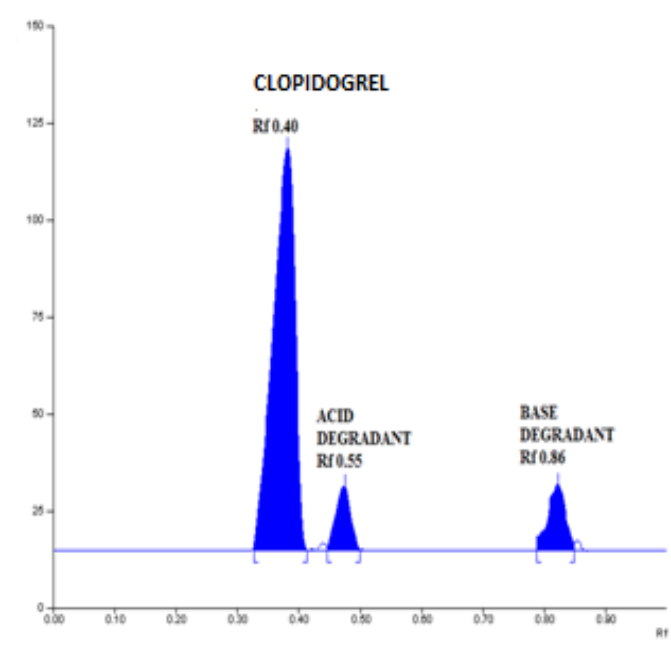

Figure 3 : Chromatogram of mixed degradation sample

\section{* Study of Linearity of response}

Aliquots portions of standard solution B (3-12 $\mu \mathrm{l})$ were applied on TLC plate and chromatograms were developed under optimized chromatographic conditions. The linear regression curves are depicted along with correlation coefficient, slope and $\mathrm{y}$ intercept. The curves were found to be linear between concentration ranges 30-120 ng/spot. 


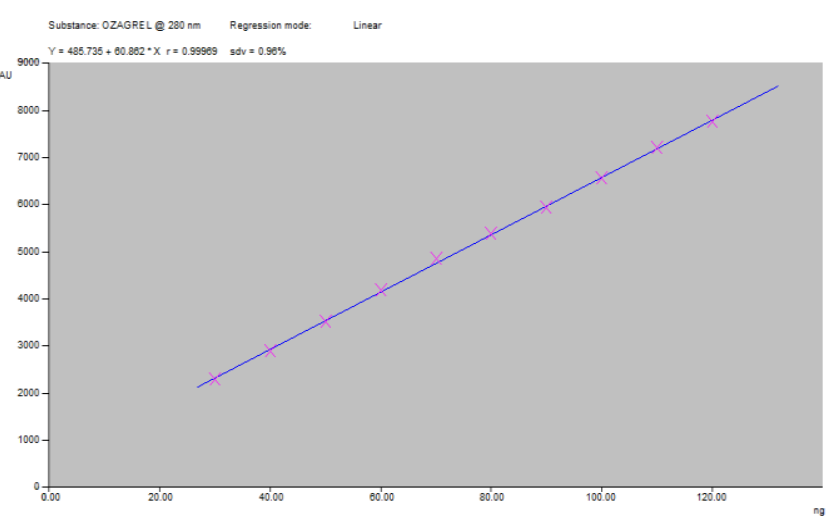

(a)

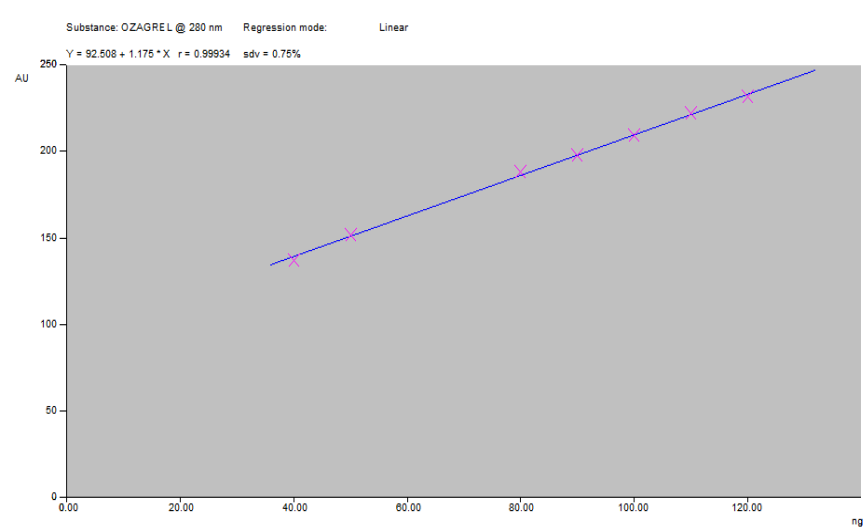

(b)

Figure 4 : Linearity (a) by area (b) by height

\begin{tabular}{|l|c|c|}
\hline Concentration range & \multicolumn{2}{|c|}{ 30-120 ng/spot } \\
\hline Parameter & Height & Area \\
\hline Slope & 1.176 & 79.862 \\
\hline Y-intercept & 92.498 & 479.765 \\
\hline $\begin{array}{l}\text { Correlation } \\
\text { coefficient }\end{array}$ & 0.888 & 0.888 \\
\hline
\end{tabular}

Table 1 : Results of Linearity studies

\section{REFERENCES}

[1]. Sethi, P. D., In HPTLC-Quantitative Analysis of Pharmaceutical Formulations, CBS Publisher and Distributor, New Delhi, IInd ed., 1996, p. 1-19.

[2]. D.H. Shewiyoa,b,c, E. Kaaleb, P.G. Rishab, B. Dejaegherc, J. Smeyers-Verbekec, Y. Vander Heyden. HPTLC methods to assay active ingredients in pharmaceutical formulations: A review of the method development and validation steps. Journal of Pharmaceutical and Biomedical Analysis, 2012, 66, p. 11- 23.

[3]. Nadig, D. E., "Preparation of drug sample for Analysis", Handbook of Pharmaceutical Analysis; Ohannesian, L., New Jersey, 2002; p. 1-3.

[4]. Sonia K, Beddi Bhavya shree, Dr.K.S.Lakshmi, "HPTLC Method Development and Validation: An Overview", J. Pharm. Sci. \& Res. Vol. 9(5), 2017,652-657

[5]. Vishal N. Kushare, Sachin S Kushare, Development of Validated Stability Indicating HPTLC Method for Assay of Ozagrel and its Pharmaceutical Formulations, International Journal of Scientific Research in Science, Engineering and Technology. NovemberDecember-2018 4 (11): 36-48]

[6]. Vishal N. Kushare, Sachin S Kushare, Sagar V Ghotekar, Development of Validated UV Spectrophotometric Method for Assay ofOzagrel and its Pharmaceutical Formulations. International Journal of Scientific Research in Science, Engineering and Technology. NovemberDecember-2018 4 (11): 69-77]

\section{Cite this article as :}

Dr. D. S. Ghotekar, Vishal N. Kushare, " Assay of Clopidogrel by Using HPLTC Method", International Journal of Scientific Research in Science and Technology (IJSRST), Print ISSN : 2395-6011, Online ISSN : 2395-602X, Volume 4, Issue 11, pp.557-561, November-December-2018. Available at doi : https://doi.org/10.32628/IJSRST12848252 Journal URL : http://ijsrst.com/IJSRST12848252 